\title{
SOCIO-DEMOGRAPHIC PROFILE AND FACTORS ATTRIBUTING TO INITIATION OF TOBACCO USE AMONG TOBACCO CONSUMERS IN BELLARY, INDIA.
}

Aravind Karinagannanavar, Wahid Khan, Bellara Raghavendra, Vandana Hiregoudar.

1. Assistant professor, Department of Community Medicine, Pushpagiri Institute of Medical Sciences and Research Institute, Thiruvalla, Kerala.

2. Postgraduate, Dept of Community Medicine, Vijayanagar Institute of Medical Sciences, Bellary. Karnataka

3. Assistant Professor, Dept of Community Medicine, Vijayanagar Institute of Medical Sciences, Bellary. Karnataka

4. Postgraduate, Dept of Community Medicine, Vijayanagar Institute of Medical Sciences, Bellary. Karnataka

\section{CORRESPONDING AUTHOR:}

Dr. Aravind Karinagannanavar

Assistant professor, Department of Community Medicine,

Pushpagiri Institute of Medical Sciences and Research Institute,

Thiruvalla, Kerala.

E-mail: draravindmbbs5@gmail.com

BACKGROUND: After China, it has been estimated by the WHO that India would have second largest number of smokers in the world. The National Family Health Survey-3, 2005-06, data revealed that $57 \%$ of adult men and $3.1 \%$ of adult women used one or more tobacco products. Among adolescent students the Global Youth tobacco survey 2006 estimated that $17.3 \%$ of boys and $9.75 \%$ of girls in India are tobacco consumers. Most common to start tobacco consumption was peer pressure and curiosity. OBJECTIVES: 1) To study the socio-demographic profile of Tobacco consumers in Bellary 2) To find the factors attributing to initiation Tobacco consumption in Bellary. MATERIAL AND METHODS: A cross sectional study was conducted among 600 tobacco consumers (Both smoke \& smokeless form) in Bellary from January 2011 to June 2011. In this Purposive sampling method was used to get the study subjects from each ward. A pre-tested and semi- structured proforma was used to collect the information. RESULTS: In the present study out of 600 subjects majority were belong to age group 19-45 years (59.1\%), were literate (58.6\%), $64.2 \%$ were using tobacco since more than ten years, around one third of the study subjects had started using tobacco before the age of 18 years. Peer pressure (49\%) was the most common reason to initiate tobacco consumption. CONCLUSION: Tobacco consumption was more among literates. Many people had started consuming tobacco in there early age only. Peer pressure was the most common reason to initiate tobacco consumption.

KEY WORDS: Initiation, Profile, Tobacco

INTRODUCTION: Tobacco consumption in one of the important behavioural risk factor for number of non communicable diseases and the mortality associated with those diseases.[1] It has been well documented that there has been an appreciable change in the global tobacco consumption trends which indicate that an estimated 930 million of the world's 1.1 billion smokers live in developing countries ${ }^{[2]}$ like India and it has been further projected that this tobacco consumption will account for $13 \%$ of all deaths in India, by $2020 .[1,3]$. In India tobacco is consumed in various forms where 
majority of them either smoke or chew tobacco (for example, paanmasala, gutka, and mishri) where in bidi smoking accounts for $40 \%$ of total tobacco consumption. $[1,4,5,6]$

Among adults, $57 \%$ of men and $3.1 \%$ of women consume one or more tobacco products (NFHS-3, 2006) ${ }^{[7]}$ and among adolescents $17.3 \%$ of boys and $9.75 \%$ of girls in the age group 13-15 are using a tobacco product [8]. Annually 800,000-900,000 Indians die annually due to diseases attributable to tobacco as reported by Tobacco control in India and as per the WHO prediction, by 2010 one million Indians will die from smoking alone and $70 \%$ of these deaths will be premature. [9] Annually the Government of India spends Rs. 30,000 crore to treat tobacco related diseases, an amount which is four times the revenue generated by the tobacco industry. [10]

Considering this huge burden it is very necessary to find the pattern of tobacco consumption and factors related to tobacco consumption and also reasons to initiate tobacco consumption. As no study has been conducted in Bellary an effort is made to explore the Sociodemographic profile and reasons for tobacco consumption.

\section{OBJECTIVES}

1) To study the socio-demographic profile of Tobacco consumers in Bellary

2) To find the factors attributing to initiation Tobacco consumption in Bellary

MATERIAL AND METHODS: A cross sectional study was conducted among 600 tobacco consumers (Both smoke \& smokeless form) in Bellary from January 2011 to June 2011, after getting ethical clearance from the institution. In this Purposive sampling method was used to get the study subjects from each ward. Bellary city has 35 wards. In each ward one tobacco selling outlet was selected randomly and information was collected from 17 or 18 study subjects from each outlet. A pre-tested and semi- structured proforma was used to collect the information on socio-demographic characteristics and the factors attributing to initiation Tobacco consumption from people aged above 14 years after taking written consent. People who are not ready to give consent were excluded from the study. Analysis was done using Epi-info software version 3.4.3.

RESULTS: The present study includes 600 subjects. Majority were belong to age group above 19-45 years (59.1\%), were literate (58.6\%) and married (88.7\%). 64.2\% were using tobacco since more than ten years, around one third of the study subjects had started using tobacco before the age of 18 years, $29 \%$ had someone in his family who consume tobacco, around two third of the study subjects purchase cigarettes and beedis in the form of packets. (Table I)

The present study shows that the peer pressure (49\%) was the most common reason to initiate tobacco consumption, followed by curiosity (14.5\%) and the least was influence of movies (Table II)

DISCUSSION: In our study we found that majority were belonging to age group of 19- 45 years, literates and married. Three fourth of the study subjects were consuming smoke form of tobacco. More than half of them were using tobacco more than ten years, one third of the study subjects had Initiated tobacco consumption before the age of 18 years only and around two third of the study subjects purchase cigarettes and beedis in the form of packets. Many studies were done across the world, among them a study of S V Subramanian et al, 1998-99, showed an association between 
tobacco consumption and socio economic markers both at the level of individual and household level where in illiterates were 2.69 times more likely to smoke and chew tobacco than those with postgraduate education. Households belonging to the lowest fifth of a standard of living index were 2.54 times more likely to consume tobacco than those in the highest fifth.[11]

In our study we found that peer pressure was one of the main reasons for tobacco consumption among young population so here teachers play a important role to educate the young population about the risk of tobacco consumption and they should be role model to the society but few studies showed that teachers also consume tobacco. Among them a study conducted by Pandey GK et al, revealed that the prevalence of tobacco consumption among the teachers was $51 \%$ where in male teachers had a higher prevalence (73.9\%) compared to female teachers (13.9\%).[12]

There are many attributing factors to initiate tobacco consumption. Our study revealed that the peer pressure was the most common reason to initiate tobacco consumption and it was followed by curiosity to try new things and least was influence of movies. Similar results were found by many studies. A study on done by Malhotra $\mathrm{C}$ et al, among juveniles showed that peer group and media were the predominant influencing factors for initiation of drug use. [13]. Another study done by Bhojani U M et al, among pre-university students in Bangalore revealed that the mean age of initiation was14.7 (2.05) years and the predominant reason to initiate was peer pressure, to have fun/enjoyment and curiosity.[14] A similar finding were revealed by a study conducted by Ravishankar T L et al, in Moradabad, where in curiosity and peer pressure were main reasons for trying tobacco, apart from these reasons, the study also revealed that the parental tobacco status had a significant influence on adolescents experimenting with tobacco.[15] A study done by Deshmukh $\mathrm{P}$ et al, among adolescents in rural Wardha revealed that the among boys peer pressure (51.2\%), feeling better (35.2\%), to ease abdominal complaints and dental problem (5\%) were the common reasons for tobacco consumption where as in girls teeth cleaning (72\%) was common reason for consumption of tobacco. In the same study focus group discussion revealed the peer pressure acts as pro-tobacco influence among boys who are outgoing and spend more time with their friends.[16]

Govt. of India has taken many innovative steps and also legislations were made to combat the drug abuse among young population but Inspite of the best efforts still young population can easily access to the tobacco products. So there is a need of community participation, Intersectoral coordination and strict implementation of laws to tackle this problem.

CONCLUSION: In our study we found that tobacco consumption is more among people productive age group, literates and married. Many people had started consuming tobacco in there early age only and few had family history of tobacco consumption. Many people purchase cigarettes and beedis in the form of packets that leads them to consume more quantity. The present study shows that the peer pressure was the most common reason to initiate tobacco consumption, followed by curiosity.

ACKNOWLEDGEMENT: The Authors' thank all the students of VIMS Bellary who helped for the study. The authors are also grateful to authors/editors/ publishers of all those articles, journals and books from where the literature for this article has been reviewed and discussed.

\section{REFERENCES:}

1) World Health Organization. Tobacco or health: a global status report. Geneva: WHO, 1997. 
2) Jha $P$, Ranson MK, Nguyen SN, Yach D. Estimates of global and regional smoking prevalence in 1995 by age and sex. Am J Public Health 2002;92: 1002-6.

3) Kumar S. India steps up anti-tobacco measures. Lancet 2000;356:1089

4) Shimkhada R, Peabody JW. Tobacco control in India. Bull WHO 2003;81: 48-52

5) Critchley JA, Unal B. Health effects associated with smokeless tobacco: a systematic review. Thorax 2003;58: 435-43.

6) Hirayama T. An epidemiological study of oral and pharyngeal cancers in central and south east Asia. Bull WHO 1966;34: 41-69.

7) International Institute for Population Studies and Macro International. National Family Health Survey2005-06 India. Mumbai; IIPS: 2007 Sep. Volume 1.

8) World Health Organisation. Tobacco Free Initiative. Global Youth Tobacco Survey (GYTS) Report.

9) Chaturvedi P. India needs stricter implementation... Indian J Cancer. 2007 Oct-Dec; 44(4):129-30.

10) Ministry of Health and Family Welfare, Government of India. Report of the working group in health care financing including health insurance for the 11th Five Year Plan. 2006 Oct.

11) S V Subramanian. Shailen Nandy, Michelle Kelly, Dave Gordon, George Davey Smith Patterns and distribution of tobacco consumption in India: cross sectional multilevel evidence from the 1998-9 national family health survey BMJ. 2004 April 3; 328(7443): 801-806.

12) Pandey GK, Raut DK, Hazra S, Vajpayee A, Pandey A, Chatterjee P Patterns of tobacco use amongst school teachers. Indian J Public Health.2001 Jul-Sep;45(3):82-7.

13) Malhotra C, Sharma N, Saxena R, Ingle GK A study on Drug use among juveniles in conflict with the law Indian J Pediatr. 2007 Apr;74(4):353-6.

14) Bhojani UM, Chander SJ, Devadasan N Tobacco use and related factors among pre-university students in a college in Bangalore, India.. Natl Med J India. 2009 Nov-Dec;22(6):294-7.

15) Ravishankar TL, Nagarajappa R Factors attributing to initiation of tobacco use in adolescent students of Moradabad, India Indian J Dent Res. 2009 Jul-Sep;20(3):346-9.

16) Deshmukh P, Murali N, Garg B, Tobacco consumption among adolescents in rural Wardha: where and how tobacco control should focus its attention?, Indian J Cancer. 2008 JulSep;45(3):100-6. 
Table I: Socio-Demographic Profile \& Pattern of Tobacco Consumption

\begin{tabular}{|c|c|c|}
\hline Variables & Frequency $(n=600)$ & Percentage \\
\hline \multicolumn{3}{|l|}{ Age(in years) } \\
\hline$<18$ & 9 & 1.5 \\
\hline $19-45$ & 355 & 59.1 \\
\hline $46-60$ & 155 & 25.8 \\
\hline$>60$ & 81 & 13.5 \\
\hline \multicolumn{3}{|l|}{ Education } \\
\hline Illiterate & 248 & 41.3 \\
\hline Literate & 352 & 58.6 \\
\hline \multicolumn{3}{|l|}{ Marital status } \\
\hline Married & 532 & 88.7 \\
\hline Unmarried & 68 & 11.3 \\
\hline \multicolumn{3}{|c|}{ Family history of Tobacco consumption } \\
\hline Yes & 174 & 29 \\
\hline No & 426 & 71 \\
\hline \multicolumn{3}{|c|}{ Modes of purchase ( $n=445$, only for smoke form) } \\
\hline Single & 32 & 7.2 \\
\hline Loose & 125 & 28.1 \\
\hline Packs & 288 & 64.7 \\
\hline \multicolumn{3}{|c|}{ Type of Tobacco consumption } \\
\hline Smoke Form & 410 & 68.33 \\
\hline Smoke less Form & 155 & 25.8 \\
\hline Both Form & 35 & 5.8 \\
\hline \multicolumn{3}{|l|}{ Age of initiation } \\
\hline$<18$ & 189 & 31.5 \\
\hline $19-25$ & 277 & 46.2 \\
\hline $26-35$ & 95 & 15.8 \\
\hline$>35$ & 39 & 6.5 \\
\hline \multicolumn{3}{|c|}{ Duration of smoking } \\
\hline$<5$ years & 126 & 21 \\
\hline 6-10 years & 89 & 14.8 \\
\hline >10 years & 385 & 64.2 \\
\hline
\end{tabular}




\section{ORIGINAL ARTICLE}

Table II: Reasons for initiation of Tobacco consumption.

\begin{tabular}{|lcc|}
\hline Variables & Frequency $(\mathbf{n = 6 0 0})$ & Percentage \\
\hline & & \\
Reasons for initiation & & \\
\hline & & 49 \\
Peer pressure & 294 & 14.5 \\
Curiosity & 87 & 8.3 \\
To keep awake & 50 & 7.2 \\
Increase performance & 47 & 2.8 \\
Family problems & 17 & 0.8 \\
Influenced by movies & 5 & 11.5 \\
Without specific reasons & 69 & 5.8 \\
Others & 35 & \\
\hline
\end{tabular}

